\title{
Trends in social inequality in the economic and political contexts
}

\author{
Natalia Zausaeva ${ }^{1, *}$ \\ ${ }^{1}$ Altai State University, 656049, 61a Lenina ave., Barnaul, Russia.
}

\begin{abstract}
The problem of inequality has been known in society since time immemorial and has not lost its significance to this day. Moreover, in the contemporary world, it acquires the features of a global problem, attracting the attention of representatives of various sciences, primarily economists and political scientists. In this article, certain approaches of the economists and political scientists to the analysis of the issues of inequality and its consequences are considered. The author concludes that there is the convergence of their research fields.
\end{abstract}

\section{Introduction}

In today's increasingly complex world, local problems are increasingly becoming global. The very term "globalization" has been subjected to a comprehensive analysis and naturally the same all-round criticism. Nevertheless, it has not lost its significance and still remains the focus of attention of many researchers of world politics, generating many polemical themes. A. Heywood, the author of one of the most popular foreign textbooks on political science, points out in this connection, "The hottest topic of controversy about globalization is its impact on the relationship of social and economic inequality' [19]. Opponents and supporters of globalization differently see the problem of inequality. If the opponents fix the growing inequality and analyze its consequences for different regions of the world, the supporters, without denying the growing inequality, try to see positive aspects or justify its natural character in this process.

\section{Political and economic contexts of social inequality}

Trends in increasing inequality in the modern world have become the subject of study of a number of well-known economists. Among them are the French scientist Thomas Picetti, the British and American economist Angus Dieton, American economists Daron Ajemoglu and James Robinson, Joseph Stiglitz, Branko Milanovic, the British economist Mark Pennington [13], and many others. This trend was reflected in Political Science in the analysis of the impact of social inequalities on the political sphere. In particular, the growth of social inequality, according to many researchers, is a danger for democracies both within individual countries and internationally. This is written by the political scientist J.

\footnotetext{
* Corresponding author: nataza@mail.ru
} 
Goldstone [4], the transitologist K. Wenzel [6], the political philosopher F. Fukuyama [18], as well as by Russian political researchers, namely Yu. Krasin [9], V. V. Lublinsky [10], O.M. Mikhailenko [12], and many others. The problem of inequality has been actualized in recent years in connection with a series of the revolutions called "colored," reflected in the works of such researchers studying revolutions as J. Goldstone [5], V. D. Solovei [15], and others.

Analysis of the problem of inequality and the patterns of its change in the contemporary world is increasingly becoming interdisciplinary. The interaction of representatives of political and economic sciences in the study of inequality is becoming more intense, but has not yet found an adequate interpretation in the social sciences. Therefore, the purpose of this study is to identify the relationship between the analysis of trends in inequality by researchers from economic and political sciences.

British scientist Danny Dorling in his book "Equality" indicates that today almost no one studies equality, a huge number of people are interested in inequality $[8$, p. 8]. This is clearly seen in the case of many studies in the twentieth century that see the problem of inequality not only in domestic politics, but also at the international level. New methods and the accumulation of data on inequality in many countries over a great historical period allowed us to identify patterns in the dynamics of inequality.

An American economist, an emigrant from Russia, Simon Kuznets in 1954 put forward the hypothesis that in countries in the early stages of economic development, income inequality first increases, but it tends to decline as the economy grows. This hypothesis, drawn up in the form of a curve line, was called the law or the "Kuznets curve" [17]. The Kuznets hypothesis has caused a lot of controversy, refutations, checks, but for a long time remained an important moment in the interpretation of the change in inequality in various countries.

However, a few years ago there was a different interpretation of the change in inequality in the modern world. It is set out in the book of the French economist Thomas Picetti "Capital in the Twenty-First Century" [14]. Its essence is in several conclusions. Before World War I, income inequality grew in most countries, but the war and the ensuing instability led to the destruction of large European states, which led to the equalization of incomes. The society became more egalitarian. After the Second World War, income equalization again occurred due to the implementation of social programs in many countries. At present, inequality has increased again and reached the level of the beginning of the twentieth century. From this fact, quite legitimate assumptions about new dangers on the path of democracy in developed countries follow, since the society of high inequality in politics today means the era of robber barons and purchased congressmen. Picketti believes that the growth of inequality is due to the law, which he calls the key contradiction of capitalism. Proceeding from this, Picketti formulates the following regularity: the slower the economic growth, the more significant the role of accumulated property in increasing inequality. To save democracy in these difficult conditions, politicians should agree on the necessary taxation of the capital. In this case, Picketti proposes to introduce an annual progressive property tax of up to $10 \%$. Since Picetti has worked with the French socialists for a long time, this idea has become the subject of discussion among the European Social Democrats [20].

Nobel Prize Laureate in Economics in 2015 Angus Dieton in his "The Great Escape: Health, Wealth and the Origins of Inequality" addresses the issue of inequality in a global context. At the same time, the author emphasizes that people's health becomes "a reflection of the inequality of wealth." He analyzes the inequalities between people and countries, identifies the most significant ways to exit countries from poverty, and also tries to find answers to the question of how to help those countries that have not yet implemented the Great Escape from Poverty and Disease, including through international organizations [7]. 
One of the leading world experts on inequality, the American economist Branko Milanovic, who fixes the rapidly changing correlation in the modern world "in the levels of economic development on the western and eastern shores of the Eurasian continent (Europe and China)", deserves attention in assessing contemporary problems of inequality [11]. In the course of the changes taking place in the distribution of incomes, he believes that those countries that were in the middle of the global distribution of incomes win. And those who were below the distribution of income do not increase their real incomes. At the same time, the top layer of $1 \%$ in rich countries continues to feel excellent. The author identifies two components in the global inequality: inequality between countries and income inequality within countries. And if the first one decreases at the present stage, fixing the inequality within countries, then for the second one demonstrates growth. Thus, if the inequality of incomes in the twentieth century decreased, now it tends to increase due to the second component of inequality. The Kuznets curve cannot explain this phenomenon. The two factors reduce inequality, according to Milanovic, (a) "negative factors": wars, natural disasters, epidemics, and (b) "positive factors": more accessible education, growth of social payments, and progressive taxation [11]. Based on the interpretation of the patterns identified by Picketti and Milanovic, someone has already concluded that the global "left turn" is coming.

From the above analysis it follows that social inequality has its roots in economic life, but it also has influence on other spheres, including political ones. The fact that inequality is connected with such an important political phenomenon as democracy, was first noticed not by T. Picetti. Even in the modernization hypothesis of the American political scientist S. Lipset, which he put forward more than 55 years ago, it was argued that the movement from economic growth to sustainable democracy is influenced by a more or less even distribution of property among the citizens of the country, as well as the level of education. These conditions open the way to the improvement of political institutions. Without these conditions, with all the efforts made, progress towards democracy cannot be successful [3]. The idea of connecting inequality and democracy finds its embodiment in modern studies. $\mathrm{K}$. Wenzel, one of the authors of the collective work "Democratization," writes that the capitalist world system encourages democracy in its center and authoritarianism on its outskirts. But "it can be argued anyway that a very strong social polarization is harmful to democracy, since the polarization of groups is easily transformed into a violent struggle for the monopolization of the state" [6]. On the other hand, he believes that if resources are distributed evenly between different groups, then the hostility between them can go down. A smaller equality increases the chances of the emergence and survival of democracy [6].

Analysis of the direct connection between economic prerequisites and democracy was conducted in the two studies by well-known economists Daron Asemoglu and James A. Robinson. In the first paper, they analyze the relationship between inequality and democracy, in particular, the conflicts between the poor and the rich in society as a condition that accompanies the transition to democracy. The authors point out that such a conflict was a defining characteristic in most cases of the introduction of universal suffrage in Latin America in the first half of the twentieth century. The arrival of democracy in South Africa and Zimbabwe also resulted from a conflict between the poor black and the rich white [2]. According to their approach to understanding democratization, "inter-group inequality must influence the balance of political institutions and thereby the likelihood that society will become a democracy" [2]. The authors draw attention to the feedback, when the very process of democratization leads to a change in the principles of distribution, thereby emphasizing the mutual influence between equality and democracy.

The second, later work of these economists analyzes the origins of world inequalities between countries and regions, as well as attempts to explain the causes of poverty in specific countries. Asemoglu and Robinson formulates it as follows, "The change in the 
political regime is the key to getting out of poverty and, ultimately, the key to prosperity" [1].

Very interesting conclusions, regularities, and generalizations regarding the manifestation of political consequences of social inequality are described by the contemporary Russian researcher Y. Krasin. He focuses attention on the connection of social inequality with the type of political regime. In particular, the author claims that quasi-democratic societies polarized by social inequality with respect to the disadvantaged strata practically do not differ from absolutist and totalitarian regimes, where the mass layers are excluded from participation in politics. Drawing on the works of Western researchers, he notes some links between the regime and social inequality. According to Krasin, "In the long run, countries with high levels of inequality tend to be authoritarian. In the same place, where inequality is minimized, or democratic aspirations are high, there is a growing need and desire for democratic transformations" [9].

Very accurately, Krasin describes the impact of social inequality on the political sphere, manifested in the polarization of society, the marginalization of disadvantaged sections of society, leading to political extremism, as well as the formation of a complex of humiliation at one pole and permissiveness on the other [9].

It is difficult to add anything significant to this characteristic of the consequences of social inequality that can really be found in societies torn by social inequality. Krasin concludes that the unlimited growth of social inequality is contrary to democracy and contributes to the development of authoritarian tendencies. That is why, in societies of a democratic type, various mechanisms for regulating social inequality are developed to prevent the consequences described above [9]. In other words, the problem is to minimize social inequality.

\section{Conclusion}

Thus, the analysis shows that the boundaries between the fields of study of the inequality, in which the representatives of economic and political sciences work, turn out to be movable. Economists in their analysis of the trends of inequality inevitably come to the problems of the existence of democracy, and political scientists, analyzing negative political processes, tend to consider inequality as being caused by economic reasons.

\section{References}

1. D. Ajemoglu, D. A. Robinson, Why some countries are rich and others poor: the origin of power, prosperity, and poverty (AST, Moscow, 2017)

2. D. Asemoglu, D. A. Robinson, Economic origins of dictatorship and democracy (HSE, Moscow, 2015)

3. A. Auzan, Novaya Gazeta, 121 (2011)

4. J. Goldstone, Why Europe? The rise of the West in world history, 1500-1850 (Gaidar Institute, Moscow, 2014)

5. D. Goldstone, Revolutions: a very brief introduction (Gaidar Institute, Moscow, 2015)

6. K. V. Harpfer, P. Bernhagen, R. F. Inglehart, K. Welzel, Democratization: a training manual (HSE, Moscow, 2015)

7. A. Diton, The great escape: health, wealth, and the origins of inequality (Gaidar Institute, Moscow, 2016)

8. D. Dorling, Equality (Knigovek, Moscow, 2014) 
9. Yu. Krasin, Svibodnaya Mysl, 2 (2006)

10. V. V. Lublinsky, Political Studies, 5 (2015)

11. B. Milanovic, Global inequality: a new approach to the era of globalization (Gaidar Institute, Moscow, 2017)

12. O. M. Mikhailenko, Vlast, 1 (2015)

13. M. Pennington, Classical liberalism and the future of social and economic policy (Mysl, Moscow, 2014)

14. T. Picetti, Capital in the 21st century (Ad Marginem, Moscow, 2015)

15. V. D, Solovei, Revolution! Fundamentals of revolutionary struggle in the modern era (Eksmo, Moscow, 2017)

16. 16. D. Stiglitz, The price of inequality: how does the stratification of society threaten our future (Eksmo, Moscow, 2015)

17. I. V. Filatov, Social and economic transformation in Russia (MONF, Moscow, 2001)

18. F. Fukuyama, The end of history and the last man (ACT \& Ermak, Moscow, 2004)

19. E. Haywood, Political Science: a textbook for university students (Yunity-Dana, Moscow, 2005)

20. D. Shestakov, Novaya Gazeta, 129 (2015) 